Near finalised version of:

A M Williams and V Baláž (2008), International mobility, learning and knowledge transfer: a case study of Slovak doctors, Social Science and Medicine, 67: 1924-33

\title{
"INTERNATIONAL RETURN MOBILITY, LEARNING AND KNOWLEDGE TRANSFER: A CASE STUDY OF SLOVAK DOCTORS"
}

\section{A M Williams and V Baláž}

\section{Abstract}

International mobility provides opportunities for learning and knowledge transfer by health care workers, with significant potential benefits for countries of destination and, in the case of returned migration, countries of origin. This is examined using a typology that recognizes four types of tacit knowledge: embrained, embodied, embedded, and encultured. There are, however, constraints to learning and knowledge transfer in the form of professional and social recognition as well as language barriers and power relationships.

These theoretical ideas are explored through a case study of internationally mobile Slovak doctors after their return to Slovakia. Individual learning and knowledge sharing with colleagues, both abroad and after return, are analysed through in-depth interviews.

\section{Introduction}

'Health worker migration is an inescapable feature of the health sector' (Bach, 2003: 31) but there has been relatively little research of mobility as a conduit 
for learning and knowledge transfer. The research deficit is particularly marked for returned migrants, an increasingly important group both because of growing mobility, and shifts to more cyclical (King, 2002) mobility - but see Brown and Connell (2004). Their experiences pose questions about the multidirectional nature of learning and knowledge transfer both while abroad and on return.

The traditional starting point for analysing knowledge is Polanyi's (1966) distinction between codified and tacit knowledge, but Blackler's (2002) typology provides a more nuanced perspective, identifying four types of tacit knowledge: embrained, embodied, encultured and embedded. These also accord with the complex mixture of knowledge - a combination of technical, managerial and cultural - required of doctors.

The paper also seeks to broaden understanding of the geographical range of cycles of health care mobility. The research literature has largely focussed on migration from Less Developed to Advanced Capitalist economies (DRCMGP, 2006). However, despite significant cultural and linguistic barriers amongst European countries (Jinks et al, 2000), EU enlargement and mutual recognition of qualifications has facilitated substantial flows of health care workers, especially from pre 1989 state socialist countries, to Western European countries (Bach, 2003). Slovakia provides a case study of these new forms of mobility (see Baláž, Williams \& Kollár, 2004). There is probably greater external recognition of the knowledge of doctors from Slovakia - which has relatively well-developed health services - than for doctors from less 
developed countries, yet their experiences do illustrate the complexities and asymmetries of medical knowledge transfer.

The transfer of medical knowledge via mobility is not an exercise in unfettered learning and knowledge transactions but - as with all workers - is mediated by multi-level regulations, institutions and practices (Williams \& Baláž, 2008). There are well structured and asymmetrical channels for mobility (determined by wage differentials, scholarships, and discourses about the location of 'advanced' knowledge) which bring medical workers from 'less' to 'more' developed health care systems, with very little mobility in the opposite direction. This strongly mediates resulting knowledge transactions - inward movers are seen as coming to learn, rather than to co-learn let alone to transfer knowledge. It also poses questions about the extent to which medical knowledge is transferable across borders by returnees.

The paper first explores key issues relating to health care migration and the conceptualization of knowledge transfer via mobility, and then outlines key features of the Slovak health services and our methodology. It then considers the migrants' learning and knowledge transfer experiences abroad, and their experiences of knowledge transfer on return, drawing on 24 in-depth interviews with returnees and hospital managers. The sample size means the findings should be considered as a case study that illustrates some of the complexities, as well as the unfulfilled potential, of migration and medical knowledge transfer. 


\section{Health Care Migration and Knowledge Transfer}

International migration of health care workers is well established, and in the 1970s an estimated $6 \%$ of doctors worked abroad (Meija, Pizurki \& Royston, 1979). However, health care labour markets have become increasingly internationalised (see Buchan and Dovlo, 2004, p271 on the UK) for several reasons, including enhanced electronic communication and job applications, targeted recruitment drives, and the need for international mobility to meet short-term recruitment shortages, given time lags in expanding medical training (Stilwell, Diallo, Zurn, Vujicic, Adams \& DalPoz, 2004). We know far less about returned migration by health care workers, not least because the distinction between temporary and permanent migration is often blurred (Chanda, 2002). However, generic migration studies have highlighted the growth of temporary migration (Dustmann \& Weiss, 2007).

High levels of international mobility provide a potentially significant conduit of learning and knowledge transfer. This paper focuses on four different types of knowledge, identified by Blackler (2002), drawing especially on his earlier work and that of Zuboff (1988), Berger \& Luckmann (1966), and Brown \& Duguid (1991):

- Embrained knowledge, which depends on conceptual skills and cognitive abilities, allows recognition of underlying patterns, and reflection on these. For mobile doctors, this may include classroom and library-based learning in more advanced medical institutes. 
- Embodied knowledge results from practical thinking and learning by doing, being rooted in specific contexts, physical presence, and sensory information. This may include learning from observation at, or participation in, particular health care events, such as surgical procedures or consultations.

- Encultured knowledge emphasizes that meanings are shared understandings, arising from socialization and acculturation. This involves learning about different values and approaches to health care, whether by doctors, other health care professionals or patients.

- Embedded knowledge is embedded in contextual factors, including shared knowledge generated in different organizational cultures and work groups. This includes learning about different health care systems, and contrasting organizational approaches to health care.

This typology is particularly appropriate in studying health care mobility because it recognizes the range of knowledge required of doctors: technical skills, academic knowledge, cultural knowledge, management know-how and administrative skills.

The question is whether migration and mobility provide a selective and/or distinctive conduit for learning and knowledge transfer. As argued elsewhere (Williams, 2007b), embrained and embodied knowledge are encapsulated in 
the individual, and are transferable via international migration. Of course, such knowledge can also be transferred electronically, but physical co-presence is useful, and probably necessary, for transferring some knowledge, such as 'learning by observation’ or 'learning by participation’ at a consultation. In contrast, encultured and embedded knowledge are place specific, being forms of socially-situated knowledge and institutionally specific. They are grounded in relationships between individuals, in particular settings and in socialization processes. The lack of shared meanings, with those working outside these settings, constrains the transfer of such knowledge via human mobility. However, migrants can transfer truncated encultured and embedded knowledge, which can be discussed with others, even if they fully lack shared understanding. Moreover, knowledge of different systems and cultures increases migrants' potential for reflexivity - comparing and contrasting - in new settings. Returned migrants, depending on length of absence, already possess substantial encultured and embedded knowledge of the return setting.

The key question is whether internationally mobile doctors have potential to learn and transfer knowledge different to that available in the origin or the return setting. There are three issues here. First, mobile doctors may have opportunities to learn different techniques or approaches in some countries - because of differences in what constitutes relevant medical knowledge, or time lags in international dissemination of medical knowledge. The internet and increasing numbers of conferences mean there are other ways of acquiring knowledge, but sometimes - for example, embodied 
knowledge - this requires co-presence. Secondly, migrants have distinctive opportunities for what Marsick and O'Neil (1999, p163) term the Critical Reflection School of Action Learning: 'Critical reflection can also go beyond the individual participant's underlying assumptions and can lead specifically to the examination of organizational norms'. This has particular relevance for embedded and encultured knowledge. Thirdly, there are opportunities as potential boundary spanners, because boundaries (here understood as national borders) are 'areas of unusual learning, places where perspectives meet and new possibilities arise' (Wenger, 2000, p223). Crossing boundaries does not automatically make an individual a boundary spanner, but can be significant where international borders demarcate significant knowledge divides.

While there is considerable scope for knowledge transfer and learning via mobility, both migrants and returned migrants may encounter substantial barriers. First, whether the organization - a hospital in this case - is willing 'to embrace external reference standards and methods' (Earl, 1990, p742) is critical. In health care this is regulated at the national level by the state and by professional organizations (Bach, 2003), although to varying degrees, partly depending on the extent to which provision is privatized. At the level of individual hospitals, both formal management strategies and styles, and individual behaviour, influence learning and knowledge transfers (Ipe, 2003, p349). Organizations need to maximize connectivity and openness amongst workers to leverage migrant knowledge transfers. 
Secondly, there are barriers related to ascription, acceptability and suitability (Jenkins, 2004, p153). Migrant doctors may be ascribed as outsiders, newcomers, or - in some cases - as ethnic minorities, influencing their acceptability to other employees. Suitability emphasizes achieved or acquired characteristics; migrants have more power to change these (including acquiring encultured and embedded knowledge over time), but social recognition of suitability may be constrained by ascription and acceptability. Issues around race and ethnicity in health care employment are well documented (Larsen, Allan, Bryan and Smith, 2005; Raghuram \& Kofman, 2002), but the experiences of 'other white' migrants are under-researched. Returned migrants may also be ascribed as outsiders in some circumstances, depending on length of absence, but are more likely to achieve acceptability.

Thirdly, migrants, like most newcomers, are often ascribed a peripheral position within work groups (Lave \& Wenger, 1991). Effective knowledge mobilization requires that newcomers move 'incrementally along a continuum from the domain of stranger toward that of friend' (English-Lucek, Darrah \& Saveri, 2002, p97). Acquiring encultured and embedded knowledge (originating within an organization) facilitates this. Again, returned migrants face fewer long-term barriers than migrants.

Fourthly, language competence is central to inter-cultural communication, which mediates the negotiability of knowledge by international migrants. According to social learning theory, language is critical to learning, since it is the main way of acting in contemporary organizations (Elkjaaer, 2003, p43). 
Language mediates doctors' ability to interact with patients, colleagues, managers, and the embedded knowledge of employer organizations.

Fifthly, knowledge transfer both shapes and is shaped by power relationships. Kelly and Lusis (2006) have demonstrated the value of Bourdieu's notions of capital and habitus for understanding migrants' experiences. In particular, the valuation of individuals' economic capital, social capital (networks and connections that can be mobilised), and cultural capital (symbolic assets) is determined by habitus (the framework or social rules which determine worth). Migrants move from one habitus to another and there is an 'exchange rate' between these (Bauder 2005). While Bourdieu's conceptualisation has its critics, it is useful in signposting key issues in mobile doctors' experiences. Their learning experiences abroad are conditioned by their social and cultural capital - the hospitals and countries they come from, and their connections to individuals in host institutions. Their power to challenge the habitus in these settings is limited. As return migrants, they also have distinctive social and cultural capital - indeed, a 'successful' migration is itself a powerful symbolic asset. Whether these capitals are recognized, on their return, depends on the 'exchange rate' in that particular habitus. Their positions within the rules of the game are shaped by their seniority and their connections, although this is not fixed: in the longer term they can challenge the multi-layered habitus, if they rise to senior positions.

Although this section of the paper has identified several ways in which migrants and return migrants can contribute to the distinctive and selective 
transfer of knowledge, and the formidable barriers they can encounter, there is no simple model of mobility and knowledge transfer. Instead, the experiences of migrants depends on the purpose and duration of their sojourns, the countries they come from and go to, their visas and the recognition of their qualifications, whether they work in rural or urban areas and in the private or public sectors, as well as career stage. They are also shaped by changes in the health care system, as illustrated by Slovakia.

\section{Health Care in a Transition Economy: Slovakia}

Martineau, Decker \& Bundred (2002, p10) assert that 'High tech' skills will only be valuable in the health sector if the returnee has access to similar working conditions and equipment'. This is more likely in middle than in lowincome countries and - by extension - the transition economies of Eastern Europe, such as Slovakia.

The post 1989 transition from a late state socialist economy and health system to marketisation and EU membership rapidly changed the health care context for migration and return. The pre 1989 state health system in the former Czechoslovakia was relatively well funded (Hlavacka, 2004, p11). However, inefficient resource allocation meant a lack of capital investment, obsolete equipment and facilities, low salaries, and oversupply of doctors.

Since 1989, Slovakia has struggled to devise a coherent health services strategy given tight resource constraints (Hlavacka, 2004, p13). Despite 
increased private funding, the state still provides $90 \%$ of resources. There has been a shift to social health insurance but the health system has become increasingly indebted because of poor collection compliance. Funding remains problematic: health care accounted for only $5.7 \%$ of GDP in 2002 , placing Slovakia fifth from bottom in the EU25 rankings. Health care reforms have also been problematic, with high levels of staffing and rising expenditure on drugs (Nemec \& Lawson, 2005). These problems were particularly acute in hospitals. Recent introduction of patient fees has stemmed demand significantly but financial constraints persist (Pažitný \& Zajac, 2005).

The number of doctors increased from 14,187 FTE in 1980 to 16,997 in 2002, and the density of active physicians (3.2 per 1000) was close to the EU-15 average (3.5) in 2001. The medical faculties determined the numbers of graduates, resulting in an erratic but general overtraining of doctors compared to vacancies. Relatively low wages - doctors' wages in 2001 were just over twice the average Slovak wage (Pažitnỳ, 2007, p7) - created fertile conditions for emigration (ILO, 2002), especially as nominal wages in France and the UK were ten times higher. Consequently, some 1400 'proof of good repute certificates' were issued for Slovak doctors registering to work abroad, 20047, compared to about 500-800 doctors graduating per annum (Žurnál, 2007). EU membership, post 2004, has also facilitated mutual recognition of qualifications and the out-migration of doctors (Jinks, 2000). The migration picture is, however, complex, for Slovakia's medical faculties also attract foreign students, who accounted for $10 \%$ of all undergraduate medical students in 2006 (UIPS, 2007). This underlines the relatively high quality of 
medical training, and existence of a reservoir of medical knowledge in Slovakia.

\section{Methodology and Profile of Interviewees}

The lack of accurate and consistent secondary statistics on health worker mobility is generalised, with data more likely to be available for destination (via registrations) than origin countries (Stillwell et al, 2004, p596). This is even more pronounced for returnees, who are often 'invisible' in most national data sets. This study draws on primary data, opting for a qualitative (in-depth interviews) rather than a quantitative approach, for two main reasons. First, in the absence of reliable lists of returnees, it would have been difficult if not impossible to distribute questionnaires to this cohort. Secondly, in-depth interviews provide understanding of migrants' 'discursive consciousness' (Robinson \& Carey, 2000), which is particularly important given the complexities of learning and knowledge.

Twenty four interviews were undertaken in 2006, 19 with doctors who had spent a significant period working/studying abroad, and 5 with hospital managers, all of whom had medical backgrounds. The managers provided overviews of the value of international working/training experiences. The first doctors were contacted through the recommendations of managers and others, and snowball methods identified other returnees. Interviews were undertaken face to face with a range of doctors. Nine were from faculty medical hospitals in the capital city, Bratislava, and Martin (a large city in the 
centre-north); these doctors have more research functions, and stronger international contacts. The other 10 interviews were undertaken in widely distributed smaller hospitals in the north and east, including a military hospital. Interviews were mostly in Slovak, but occasionally in English as one researcher did not speak Slovak. Given the relatively small number of interviews, the study should be considered as illustrative of the complexities and contingent nature of migration and knowledge transfer. English language translations of the interviews were read and re-read several times, and were subject to thematic analysis, whereby we focussed on what was said rather than how it was said. Typologies of narratives were built up around different knowledge-related themes, as a basis for theorising. Given the sample size, this was done manually rather than using qualitative analysis a software.

There is a spectrum of international mobilities, ranging from spending a few days at a conference, through week-long training courses, to long-term migration. Our target population was doctors who had significant learning or knowledge transfer experiences abroad. However, as this could not be known before the interview, we defined a minimum time period abroad for identifying potential interviewees. Interviews with managers suggested that three months studying and working abroad was the minimum for significant and effective learning. Doctors often combine studying and working, so we did not differentiate between these. Working abroad excludes the Czech Republic, which until 1993 was joined with Slovakia in Czechoslovakia. 
In common with most studies of returnees, we can not comment on the experiences of those who have not yet returned, and perhaps never will. Their precise number is not known, but Manager One estimated that in his medical field 2-3 of the 12-18 doctors who had been abroad had not returned. Manager Three, who had seven doctors in his clinic, commented that only one had been abroad for more than a short-term placement, and none had left permanently. We have no data on newly graduating medical students who may have gone abroad to work, but there are general indications of a relatively high propensity to return. Most interviewees had spent relatively short periods abroad: six spent 3-4 months and another five had spent up to one year, while eight had spent longer periods up to a maximum of four years. There were more men (12) than women (7), reflecting highly gendered experiences of mobility, due particularly to social expectations about child care.

Their collective mobility experiences span the economic and political transition in Slovakia. Three interviewees had first been mobile under state socialism (pre 1989), which conditioned their destinations: Libya and Hungary in these instances. However, it was possible - if exceptional - to work/train in western countries, and a doctor who had been to Hungary subsequently worked in the Netherlands and Germany before 1989. Since 1989, as national and EU scholarships, and other possibilities for working or training abroad, have increased, doctors' mobility has been reoriented to western countries; particularly Germany, Austria, Switzerland, and the Netherlands, but also the UK, USA and France, and Oman. The destinations were influenced by 
proximity, networks, and language competence (German and English, mainly). Institutional links are also important in medical migration (Bach, 2003). Two army doctors had served on UN missions to East Timor and Cyprus.

To maintain anonymity, we refer to individual doctors by numerical codes, D1D19.

\section{Learning Experiences Abroad: in Pursuit of Health Care Knowledge?}

Motivations: Remuneration and Professional Development

Slovakia has a relatively modernised if under-funded health service and doctors' wages are relatively low compared to Western Europe. Therefore, remuneration could be expected to have motivated mobility, but only three doctors mentioned this, reflecting the relatively short periods that most had spent abroad, and that some had scholarships rather than salaried positions. There were exceptions. D4 (female, general surgery), who been to Libya in the 1980s, explained that although motivated by higher wages, her destination choice had been constrained by the mediation of Polytechna, the state foreign trade enterprise.

Professional development was the principal motivation, often linked to acquiring specialist knowledge. Contacts were usually made via professional or personal networks, or close institutional relationships. For example, D18 
(male, neo-natology) had been to Switzerland because his professor had links with a prestigious Swiss centre. Some doctors, however, had more actively shaped their international experiences. D12 (female, urology) had written to many institutions before finding an opening to spend three years in the USA working on infertility treatments. And one exceptional doctor (D16, male, pathology) had already been to three countries before 1989, working on haemopathology, which then became a turning point for him:

.... two days after the changes in 1989, I was again invited to Germany .... By then some of the people I had known in Kiel had moved to Koln. I was working with what you could call 'Leonard's children' [pioneer international specialist].

Some doctors' international experiences were unplanned. Both army doctors (D5, male, general surgery and D9, female, anaesthesiology) had simply been sent abroad on UN missions to East Timor and Cyprus. Others were motivated by new experiences. D6 (female, orthopaedist), for example, had been to Oman which offered 'absolutely exotic' travel opportunities. Whatever their motives, the periods abroad represented learning experiences for all interviewees although these were conditioned by their motives, type of sojourn, and the specific institutions where they worked or trained.

Health Care Learning Experiences: from Technology to Philosophies of Care

All interviewees found something positive in their learning experiences abroad. To some extent their comments were about technology, particularly before 1989. D16 (male, pathology), who had first gone abroad in the 1970s 
to learn about haemopathology, commented that '.. we had very old instruments and equipment in Slovakia. And it was very difficult to renew or replace.' More recently mobile doctors were less likely to comment on technology, except for those who had worked in centres of excellence. D17 (male, anaesthetist) reported that in the Netherlands in the 1990s,

it was a professional revolution for me. The best gold standard was in the Netherlands. .... They had different technology, and different medicines [for haemo-dynamics] at that time.

However, most returnees did not comment on technology. D13 (male, gastroenterology, Switzerland) stressed there had been significant technological convergence since he first went abroad in 1997. The gap had also closed for other types of codified knowledge. D17 (male, anaesthetist), who had been to the Netherlands and Sweden, stressed changes in accessing medical literature:

Back in the 1990s there was a lack of books, and there was no internet. If I bought a book then it cost 25,000 koruna which was my salary for a month, so my family would starve..... Now we have the internet so there are no real differences in medical knowledge.

However, the diminishing gap in technology and codified knowledge has increased the relative importance of tacit knowledge acquisition. This can be seen in terms of Blackler's (2002) four main types of tacit knowledge. Although often blurred and overlapping in practice, they are presented separately here for analytical convenience. The respondents, of course, did not refer to these abstract conceptualisations, but to particular experiences and events. 
Some doctors considered that they had not acquired any new embrained knowledge, commenting that knowledge about techniques, medicines and approaches were now widely available whether from international conferences, books or - most importantly - the internet. However, codified knowledge was not always considered sufficient, as D9 (female, anaesthesiologist) explained about her experiences in East Timor: 'I saw many tropical diseases, I had only known from books.' Those who responded positively tended to refer to particular techniques they had gone abroad to learn about. Examples included spinal fusion techniques in the USA, and immunisation chemistry in Germany. D18 (male, neo-natology) explained that Switzerland not only had different equipment, but 'a very complex approach to the care of new babies. So I supposed that I learnt a new philosophy of care..' Arguably, it is the full system of care which is most difficult to encapsulate in codified knowledge.

Several doctors were even more emphatic about acquiring embodied knowledge. At one extreme, this only represented opportunities to practice diagnostics and interventions with a larger number and range of patients than in Slovakia, as D7 (male, ophthalmologist) recounted from Germany: 'In Slovakia learning would have taken much longer'.

A similar point was made by D15 (male, neurology) about working in the UK on neuro-muscular diseases: 'The main difference is that we only had one machine while there were four to work on in London'. D2 (male, cardiology) 
commented more positively on being able to practice up to date angiosurgery medical interventions: Being present, observing, practising were all important forms of learning, or of acquiring embodied knowledge as explained by $\mathrm{D} 13$ (male, gastroenterology) in relation to working in a transplants clinic in Switzerland:

You observe similar operations, similar diagnoses and patients and similar solutions - but! - you see minor differences, which are not mentioned in books. ... And I really did. You can see it and imitate it, because this is a practical matter.

Even doctors who did not consider that they had acquired embrained or embodied knowledge, acknowledged acquisition of embedded or encultured knowledge. Embedded knowledge was mostly discussed in terms of management and organizations. For many interviewees, learning about systems of patient care was most important. D13 (male, gastroenterology) who had worked in surgery in Switzerland commented:

'in my country I couldn't see the system they use in Switzerland. It is very complex - the treatment of a particular diagnosis, consulting with other clinics in the same hospital, and interdisciplinary meetings.'

In Hungary, mental health care was organized differently to Slovakia:

'In Slovakia we use more drugs, and they are less specific drugs. The Hungarians spend more time speaking to their patients. You can read about these things in books but you really do need to see how they do things'.

Encultured knowledge was also valued. In part interviewees focussed on openness to new ideas and learning. For D17 (male, anaesthetist), the main 
difference between Slovakia and Sweden was a commitment to continuous learning, especially because of rapid changes in medicine. And D18 (male, neo-natology) valued the fact that his Swiss institute was full of people who had worked in other countries, and were open and internationalised. There was also the reflective knowledge that came from comparing different systems, which D17 illustrated in terms of patient attitudes in Sweden.

Western European patients know more about their diseases. In Slovakia, patients and relatives don't really communicate with doctors... It's not part of our training or work culture - or even of our national cultures.

All the Slovak doctors reported learning experiences while abroad. For some, this involved accessing technology, but mostly they valued acquiring tacit knowledge. Embrained and embodied knowledge were particularly valued by those who had gone abroad to acquire specialised training - learning by observation and learning by doing were important. However, encultured and embedded knowledge were also significant, learning through comparisons with Slovakia, whether in terms of management systems, attitudes to learning, or the culture of patient care. Even those who felt that they had learnt little that was new about health care techniques considered that they had learnt about different approaches to health care.

Barriers to Learning: 'Outsiders' and Language

Bach (2003) suggests that the most important barriers to pursuing careers abroad include registration and licensing, discrimination over jobs and pay, the uncertainties of fixed term contracts, and vulnerability as foreign workers; 
international doctors are often disproportionately found in lower grade posts, and less popular specialisms (Unwin 2001). As a profession, doctors are different from, say, IT specialists who work in a sector with relatively few national regulations on professional practice. Mobile doctors can also face obstacles to learning.

In contrast to these earlier studies, about one half (10 of 19) of the Slovak interviewees reported that they had encountered no major and sustained problems while abroad, although there were sometimes initial difficulties. Where initial obstacles were encountered, these were as likely to be social as professional; it was nine months before Swiss doctors had started to socialise with D18 (male, neo-natology).

In contrast, almost one half of the interviewees had encountered more persistent or significant problems. D3 (male, neurosurgery, USA) and D10 (male, orthopaedics, Germany) complained about the costs of living, and poor quality accommodation, which had impacted on their studies. Maintaining relationships with families and friends was not reported as a problem, perhaps because of their relatively short sojourns.

A small group (3) reported either hostility or discrimination in the workplace. The most severe was D2 (male, cardiology) in Germany, who considered he had been 'horribly abused' by the hospital, working long unpaid overtime hours and, as a Slovak, being treated as inferior to German doctors. D17 
(male, anaesthetist) reported contradictory experiences of being an outsider, while forming a deep attachment to his clinic manager in the Netherlands.

In this particular habitus, social and cultural capital had contradictory valuations, so that two of the three doctors reported positive learning experiences, despite their status as 'outsiders'. Of course, Slovak doctors, whether working in Europe or the USA, did not by and large face two common obstacles. First many were on relatively short sojourns, or on training visits, and may not have been seen as rivals by their colleagues. Secondly, despite comments about being considered 'exotic', they had not encountered the systematic discrimination encountered by some ethnic minorities. In other words, either it was considered that the rules of the game did not fully apply to them, or their cultural capital was relatively positively valued.

Although most doctors had not felt excluded or discriminated against as outsiders, language competence was a potentially significant barrier to learning and career advancement. Just over one half (10 of 19) reported some language difficulties. This was important because language is crucial to practice (D8, male, general surgery, USA) and to filling in reports and other medical forms (D6, female, orthopaedist, Germany). Communication with colleagues seems to have been less problematic, although dialects sometimes constituted barriers. German and Swiss German dialects were particularly difficult to understand, as was the Scottish dialect. Occasionally, the doctors had virtually no command of the language of the host country. D16 (male, pathology) in the Netherlands, had hoped to be able to speak 
German but couldn't, and had to learn English 'really quickly. I didn't attend any classes. But I shared a flat with English colleagues, and we slept together, worked together, spoke English together. Language barriers did pose challenges for some doctors, but they were resourceful in overcoming these, and none reported that this hampered their longer term learning and working.

Social Recognition of Prior Healthcare Knowledge

We also explored whether the doctors had transferred knowledge to their foreign colleagues. Some of those who had been on training courses did not think that this was appropriate, suggesting that neither they nor their foreign colleagues considered they were potentially significant in knowledge transfer. Amongst the others, the balance was positive (six out of nine). The two strongest critics both commented on lack of social recognition experiences in Germany: one of these, D6 (female, orthopaedist) commented that 'German colleagues - but not many actually - showed sour faces when speaking with anybody from the East'.

In contrast, several interviewees considered their knowledge was socially recognized. This mainly related to embrained knowledge. For example, D2 (male, cardiology) considered that '/ had rich theoretical knowledge of vein surgery and some older German colleagues, who specialised in cardiosurgery, were pleased to learn from me'. Probably the most positive experiences was reported by D18 (male, neo-natology, Switzerland): 
Perhaps I knew even more in some areas because I had three attestations. Two in paediatrics and one in nephrology. I combined them in paediatric nephrology. I gave this to the Swiss and they gave me a certificate.

Of course, these experiences were contingent and D10 (male, orthopaedics), for example, commented that 'I was lucky that my German friends occupied high positions, so other German colleagues recognised me'. But Slovak medical schools have a generally sound reputation and many doctors had considerable experience of practice before working abroad.

In summary, some doctors had transferred knowledge to colleagues abroad. The fact that most had been unable to do so partly reflects their perceptions that they had gone for (uni-directional) learning . However, there were instances of knowledge transfer, mostly of embrained knowledge. There was also some recognition of embodied knowledge, acquired through extensive learning by practice in Slovakia. However, none of the interviewees considered that their hosts had sought to acquire encultured or embedded health-care knowledge from them. This lack of social recognition also hampered the learning of some doctors abroad, although none of the interviewees were entirely negative on this point. But their experiences were contingent on their social and cultural capital, and the particular habitus that they were working within.

\section{Returned Mobility and Healthcare Knowledge Transfer}


Changing individual practices: a contribution to healthcare internationalisation

Arguably there has been an 'internationalisation of the professions' (Lenn \& Campos, 1996) indicating a shift from national to international standards and, by extension, greater internationalisation of knowledge. This applies to medical knowledge dissemination whether in paper or electronic formats, and the growth of communities of practice (Wenger, 1998) amongst health practitioners. As noted earlier, some interviewees recognised this when commenting on convergence between Slovakia and western Europe in terms of equipment and theoretical knowledge. However, all interviewees also considered they had acquired tacit knowledge abroad. This was recognised by hospital managers, with Manager One commenting: 'I would like it to be an obligation because they can learn so much abroad'. One interviewee (D18, male, neo-natology, Switzerland) similarly reported that his foreign mentor had urged him to 'go home and disseminate what you know', rather than accept another fellowship at his clinic.

The doctors were overwhelmingly positive (14 of 19 ) about how international experiences had influenced their work after returning. Of the four who were negative (one was ambivalent), two were completely negative even though they had acquired new knowledge abroad. Of the remaining two, one considered that she had improved her self confidence, and another that her life had been changed, but not her professional work. 
Amongst those who were positive, embrained and especially embodied knowledge were valued. D8 (male, general surgery) had acquired new surgery techniques relating to pancreas and liver interventions: 'American doctors are much more careful with soft tissues and don't use such aggressive techniques'. There were also positive comments about how new embedded knowledge had influenced their work, but no specific mention of encultured knowledge. This was confirmed by Manager 3 who commented that: 'the older generation of doctors had an ad hoc approach while the newer generation who have worked abroad are more systematic'. As argued elsewhere (Williams, 2007b), migrants can transfer only truncated versions of embedded knowledge, but this is given added value by reflexivity. As D13 (male, gastroenterology) explained about Switzerland:

It's good to go somewhere and see how the different system operates..... When you return home, you can compare procedures and think about whether you should change your routines or not. Sometimes it pays, sometimes not.

Others, such as Manager 2, valued overseas sojourns as a means of developing new social networks, a form of embedded knowledge. Not surprisingly, returnees who were now in senior positions were positive about junior colleagues going abroad.

Inter-personal knowledge transfers: 'like mosquitoes around me'

The final aspect of knowledge and learning investigated was whether the interviewees had realised knowledge transfers to their Slovakian colleagues 
after returning. Most (14) were positive, two were ambivalent, and three were negative. One of the latter, D15 (male, neurology, UK), believed he had not acquired any new knowledge abroad, while the other two blamed their current managers for not recognizing their new knowledge. D6 (female, orthopaedist) was bitterly disappointed following her return from Germany:

I expected my colleagues would be pleased to learn about my experience. I even hoped the management would ask me to give lectures. But ... they transferred me to a post, where I couldn't use what I knew.

D17 (male, anaesthetist, Netherlands) was most positive, and considered that he had introduced new types of drugs for haemo dynamics. There were many ways in which knowledge could be transferred. If tacit knowledge was codified, it was more likely to reach a wider audience. D16 (male, pathology) explained that 'after I had been in Hungary I learnt about new ways to classify tumours, the Kiel classification. I then spent time working with Professor Y. Back in Slovakia I wrote a book on the Kiel classification'. Similarly, after returning from the USA, D12 (female, urology) had published several papers and monographs.

In addition to tacit to codified knowledge transactions, tacit to tacit transfers were more common, for example via seminars, or simply talking to colleagues informally. This was vividly expressed by D17 (male, anaesthetist): 'the young ones were like mosquitoes around me, and I was really pleased to share my knowledge [of haemo-dynamics]'. They also used their international networks as conduits for acquiring tacit or codified knowledge, if they or their 
Slovak colleagues needed advice on particular cases. D18 (male, neonatology) explained that 'If I have a patient with a rare condition, the books may suggest there are two or three treatments. So I contact Switzerland and ask their advice'.

Their comments mostly referred to embrained and especially embodied knowledge transfers. But there were also examples of sharing reflective encultured and embedded knowledge. D13 (male, gastroenterology) commented on transferring a fundamentally different approach to medical practice from Switzerland:

any opportunity to compare two systems is great. It doesn't matter if your conclusion is positive or negative - you can compare and learn. The main result is that you can think about your daily professional routines and discover new ways of doing things.

However, knowledge transfer sometimes also encountered obstacles.

Overcoming barriers: acquiring embedded knowledge

Broadly similar numbers of interviewees considered that they had (7) and had not (6) faced significant barriers in transferring knowledge on return, whether to individuals or the organization itself. Some younger doctors, who had been on relatively short training courses, did not consider this question was relevant to them. 
D12 (female, urology) was emphatic that not only had there been no significant barriers, but 'we have very good cooperation with German and Austrian urologists. They work in our laboratory sometimes'. Although others did not quote such concrete links, several considered their colleagues and managers had been open to new ideas. It helped to approach such knowledge transfer, with appropriate inter-personal skills. As D13 (male, gastroenterology, Switzerland) explained:

I did not return like an overoptimistic, energetic man, who wants to change everything. So, I had no problems, when I made smaller changes in Slovakia.

D12 (female, urology) similarly argued that :

The ideas I learnt abroad are transferable to Slovakia. OK our systems are different, but you don't need to change the entire system in Slovakia or in this hospital in order to introduce new ideas. You can improve some things.

Others were less sanguine about knowledge transfer. One obstacle was lack of funds for new technology (noted by D3, male, neurosurgery, USA). However, the most difficult problem was trying to transfer knowledge between health care systems. Indeed, D17 (male, anaesthetics) commented that he had faced more problems in adapting to returning to Slovakia to work, than in moving to Sweden. The obstacles identified were lack of organizational openness to external knowledge, difficulties of challenging embedded knowledge in Slovak hospitals, and peripheral individual positions. The interweaving of power relationships, cultural capital and contested knowledge were central to such struggles. 
D18 (male, neo-natology) encountered lack of openness after returning from

Switzerland, linking this to whether colleagues had worked abroad

Those who have been abroad are open. Those who have never been abroad scored points, saying things like 'you think you are world champion'. They don't understand what l'm talking about.

To some extent, this was about the limited power of young doctors returning to a system where many heads of section - for various reasons - were suspicious of the challenges posed by enthusiastic young returnees. D10 (male, orthopaedics, Germany) explained: 'I was too young to have an impact on the system. I wasn't the chief. You have to be powerful here [the hospital] to make changes'. But it was not only a question of seniority. The most telling example was D16 (pathology, male), a doctor with an international reputation, who had worked abroad in several countries. He recounted that:

I had become chief of the department in 1989. The Dean warned me not to go to Germany for two years - it would be a problem and I would lose my position. I hoped to be re-elected when I returned, but I wasn't. In those years the department was sleeping.

He had considered re-emigrating, perhaps permanently, but then had become Head of the Clinic and, with his new power, challenged aspects of the embedded knowledge in the hospital, and introduced new ideas.

Others believed, however, that the gap between health care systems was exaggerated. D14 (male, psychiatry), who had worked in Hungary and Austria stated: 
There are no real difficulties. My younger colleagues do accept new ideas, and my boss also accepts them. There are no big problems in moving ideas from Austria or Hungary to Slovakia. These countries were historically close and there are still lots of basic similarities.

Manager Five acknowledged these barriers, but also argued that change could be engineered: 'Medical systems abroad operate in different ways and require different way of thinking. It is sometimes difficult to apply [new ideas] in Slovakia, but if you are positive and look for ways, how it can be done, then you can do it. These insights demonstrate that knowledge transfer is both contested and socially situated. It is necessary to understand the types of knowledge being transferred - reflective embedded and encultured knowledge pose greater challenges than embrained and embedded knowledge - as well as the social and cultural capital of the individuals in each setting.

\section{Conclusions}

Existing research on health worker mobility has mostly focussed on flows from less to more developed countries, and on a few relatively open health care labour markets such as the UK and USA. However, as Bach (2003, p7) reminds us, 'Countries that in the past were fairly immune to the migration of health professionals are being drawn into an increasingly integrated global labour market'. This paper has provided insights into one of the newer foci of health care mobility, Eastern Europe, through a case study of Slovakia, while also addressing relatively neglected return migration issues. 
The paper's central focus is the learning and knowledge transfer experiences of returnee mobile doctors (long term migrants are excluded by definition), examined through the lenses of Blackler's (2002) typology of knowledge as applied to studies of international migration and mobility (Williams 2007a, b). Given the complexities of learning and knowledge, the analysis is based on qualitative rather than quantitative primary data. The small purposive sample means that we make no claims that our findings are representative, particularly given the contingent nature of migration and knowledge transfer experiences. These contingencies are evident in the particular experiences of those who went abroad before 1989 against those who went abroad after 1989 , or the differences between those who went to work abroad for several years, rather than on training courses, and the importance of country visited and career stage. Nevertheless, the analysis has provided several insights into learning and knowledge transfer via international mobility.

The first, and perhaps most important, conclusion is that discourses surrounding medical mobility tend to present this as a story of doctors, from countries such as Slovakia, seeking to learn in 'more advanced' medical systems in order to transfer knowledge back to their countries of origin. They therefore tend to be seen as learners rather than potential sources of knowledge while abroad. This was mostly the experience of our interviewees and, although there were exceptions, this represents unrealized potential for knowledge transfer in 'more advanced' destination health care systems. 
Secondly, despite a notable degree of international convergence in medical knowledge, both managers and doctors agreed that international mobility continues to be a source of significant and distinctive learning. Embrained, and especially embodied, knowledge were highly prized in their learning experiences, but so too were the perspectives provide by the encultured and embedded knowledge of different health systems. For some doctors, the acquisition of advanced specialized knowledge - much of it learning by practice or learning by observation - was the principal return from mobility, but for others it was learning about, what one doctor termed, 'different philosophies' of health care.

Thirdly, most interviewees did not experience significant barriers to learning abroad, whether on training programmes or working, perhaps because they were 'other white', rather than non-white migrants, working mostly in Europe and North America. They could also rely, to varying degrees, on their social and cultural capital. Most barriers to learning abroad were overcome after initial difficulties, for example, in terms of language competence. But a few doctors suffered persistent obstacles related to their positions as outsiders. These experiences are not necessarily those of all Slovak doctors or of doctors from other countries, particularly from the Less Developed Countries, working in Europe. Moreover experiences do depend on stage of career, how an individual is incorporated into the health service in the destination (for example, as a clinical fellow, as a short term trainee, or as a locum). Indeed, the analysis in this paper has emphasized how migrant doctors themselves 
had differing expectations of learning and knowledge transfer depending on the length and the exact nature of their period of work and study abroad.

Fourthly, their mobility experiences informed their work after returning to Slovakia, although a small number considered that they were marginalized or ignored by their managers. There were also positive stories about knowledge transfer to Slovak colleagues who, as one interviewee memorably expressed it, 'were like mosquitoes around me'. However, there were differences in the degree to which organizations were open to external knowledge, and junior and sometimes even senior - figures complained about the difficulties encountered in introducing new ideas into systems of strongly embedded knowledge, infused by centralized power structures. This can be understood in part in terms of the worth attached to their social and cultural capital in different settings. But knowledge transfer was possible, whether in codified or tacit forms, and whether involving minor changes within existing systems, or even reforming those systems.

Fifthly, while individual doctors reported significant knowledge transfers on their return, the obstacles they encountered were not only related to power struggles in particular clinics or departments. There are persistent national cultural differences, for example in the attitudes of patients, or in health service funding models, which is reflected in prevailing health care knowledge in countries such as Slovakia. We should therefore be wary of seeing mobility as an unproblematic method of transferring some idealized 'western' model of health care from 'more' to 'less' developed societies. However, mobility can 
be an important means of knowledge translation, where individuals and organizations seek to engage with the real complexities of knowledge transfer.

In terms of future research, there is need for further studies to extend this illustrative case study. But there is also need for further research using additional ethnographic methods, such as observation or diaries, to allow deeper exploration of the processes of learning and knowledge transfer. By implication, this also highlights the need to study not only migrants, but also the non-migrants with whom they interact in the countries of emigration and return.

\section{References}

Bach, S., 2003. International migration of health workers: labour and social issues, International Labour Office, Sectoral Activities Programme, Working Paper WP209, Geneva

Baláž, V., Williams, A. M. and Kollar, D., 2004. Temporary versus permanent youth brain drain: economic implications, International Migration 42 4, pp 3-34

Bauder, H. 2005. 'Habitus, rules of the labour market and employment strategies of immigrants in Vancouver, Canada', Social and Cultural Geography 6 1, pp81-97

Berger, P. and Luckmann, T., 1966. The social construction of reality: a treatise in the sociology of knowledge, Penguin, London. 
Blackler, F., 2002. Knowledge, knowledge work and organizations'. In Choo, C. W, and Bontis, N., Editors, The strategic management of intellectual capital and organizational knowledge, Oxford University Press, New York, pp 47-62.

Brown, R. P. C. and Connell, J., 2004. The migration of doctors and nurses from South Pacific island nations', Social Science and Medicine, 58 11, pp2193-210

Brown, J. S. and Duguid, P., 1991. Organizational learning and communitiesof-practice: towards a unified view of working, learning and innovation, Organizational Science, 2 1, pp40-57

Buchan, J. and Dovlo D., 2004. International recruitment of health workers to the UK: a report for DFID, Health Policy and Development, 2 3, pp 180-2

Chanda, R., 2002. Trade in health services, Bulletin of the World Health Organization, 80 2, pp158-63.

DRCMGP (Development Research Centre on Migration, Globalization and Poverty), 2006. Skilled migration: healthcare policy options, University of Sussex: Development Research Centre on Migration, Globalization and Poverty, Briefing 6, Brighton

Diallo, K., 2004. Data on the migration of health care workers: sources, uses and challenges, Bulletin of the World Health Organization, 82 8, pp601-7 
Dustmann, C. and Weiss, Y., 2007. Return migration: theory and empirical evidence from the UK, British Journal of Industrial Relations, 45 2, pp236-56

Earl, P. 1990. Economics and psychology: a survey, The Economic Journal, 100, No, 402: pp718-55.

Elkjaer, B., 2003. Social learning theory: learning as participation in social processes'. In: Easterby-Smith, M. and Lyles, M. A., Editors, The Blackwell handbook of organizational learning and knowledge, Blackwell, Oxofrd, pp 3853

English -Lucek, J. A., Darrah, C. N. and Saveri, A., 2002. Trusting strangers: work relationships in four high-tech communities, Information, Communication and Society, 5 1, pp90-108

Hlavacka, S., Wágner, R. and Riesberg, A., 2004. Health care systems in transition: Slovakia,WHO Regional Office for Europe on behalf of the European Observatory on Health Systems and Policies, Copenhagen.

ILO, 2002. Social dialogue in the health services: institutions, capacity and effectiveness, International Labour Organization, Geneva.

Ipe, M., 2003. Knowledge sharing in organizations: a conceptual framework, Human Resource Development Review, 2, 4, pp337-59 
Jenkins, R., 2004. Social identity, second edition. Routledge, London.

Jinks, C., 2000. 'Mobile medics? the mobility of doctors in the European Economic Area', Health Policy, 54 1, pp45-64.

King, R., 2002. Towards a new map of European migration, International Journal of Population Geography, 8 2, pp89-106.

Kelly, P. and Lusis, T. 2006. 'Migration and transnational habitus: evidence from Canada and the Philippines', Environment and Planning A 38 5, pp831847.

Larsen, J. A., Allan, H. T., Bryan, K. and Smith, P., 2005. Overseas nurses' motivations for working in the UK: globalization and life politics, Work, Employment and Society, 19, 2, pp349-68

Lave, J. and Wenger, E., 1991. Situated learning: legitimate peripheral participation, Cambridge University Press, Cambridge.

Lenn, M. P. and Campos, L. (Editors), 1996. Globalization of the professions and the quality imperative: accreditation, certification and licensure, Magan Publications, Madison

Marsick, V. J. and O'Neil, J., 1999. The many faces of action learning, Management Learning 30 2, pp159-76 
Martineau, T., Decker, K., Bundred, P, 2002. Briefing note on international migration of health professionals: levelling the playing field for developing country health systems, Liverpool School of Tropical Medicine, www.liv.ac.uk/lstm/hsrhome.html

Meija, A., Pizurki, H. and Royston, E., 1979. Physician and nurse migration: analysis and policy implications, World Health Organization, Geneva.

Nemec, J. and Lawson, C., 2005. Health policy in Slovakia and the outcomes of health care reforms: 1989-2003, Journal of Comparative Policy Analysis, 7 $1, \mathrm{pp} 49-71$

Pažitný, P., 2007. Shooting at a moving target', IntoBalance (Health Policy Institute, Slovakia), Issue 2/2007, 7

Pažitný, P. and Zajac, R., 2005. Health care reforms in Slovak Republic, University of Michigan, Williams Davidson Institute, Policy Brief 9

Polanyi, M., 1966. The tacit dimension, Routledge and Kegan Paul, London.

Raghuram, P. and Kofman, E., 2002. The state, skilled labour markets, and immigration: the case of doctors in England, Environment and Planning A, $\mathbf{3 4}$ 271-89. 
Robinson, V. and Carey, M., 2000. Peopling skilled international migration: Indian doctors in the UK' International Migration 38 1, pp89-108

Stilwell, B., Diallo, K., Zurn, P., Vujicic, M., Adams, O. and Dal Poz, M., 2004. Migration of health care workers from developing countries: strategic approaches to its management', Bulletin of the World Health Organization 82, $595-600$

UIPS, Ústav informácií and prognóz školstva, 2007. Statistical yearbook of education for 2006/2007, Institute for Information and Forecasts in Education of the Ministry of Education, Bratislava. Available at: www.uips.sk

Unwin, L., 2001. Career progression and job satisfaction. In: Coker, ,N., Editor, Racism in medicine: an agenda for change, King's Fund, London.

Wenger, E., 1998. Communities of practice: learning, ,meaning, and identity, Cambridge University Press, Cambridge

Wenger, E., 2000. Communities of practice and social learning systems, Organization, 7, 2, pp225-46 
Williams, A. M., 2007a. International labour migration and tacit knowledge transactions: a multi-level perspective, Global Networks, 7 1, pp1-22

Williams, A. M., 2007b. Listen to me, learn with me: international migration and knowledge', British Journal of Industrial Relations, 45 2, pp361-82

Williams, A. M. and Baláž, V., 2008. International Migration and Knowledge, Routledge, London.

Zuboff, S., 1988. In the age of the smart machine: the future of work and power, Basic Books, New York.

Žurnál, 2007. Zátka na únik mozgov \{Stopping brain drain\}, The Žurnál weekly 1, no 16, 28 June 